\title{
Antioxidant and Antiplasmodial Activities of Bergenin and 11-O-Galloylbergenin Isolated from Mallotus philippensis
}

\author{
Hamayun Khan, ${ }^{1}$ Hazrat Amin, ${ }^{2}$ Asad Ullah, ${ }^{1}$ Sumbal Saba, ${ }^{2,3}$ \\ Jamal Rafique, ${ }^{2,3}$ Khalid Khan, ${ }^{1}$ Nasir Ahmad, ${ }^{1}$ and Syed Lal Badshah ${ }^{1}$ \\ ${ }^{1}$ Department of Chemistry, Islamia College University, Peshawar 25120, Pakistan \\ ${ }^{2}$ Institute of Chemical Sciences, University of Peshawar, Peshawar 25120, Pakistan \\ ${ }^{3}$ Departamento de Química, Universidade Federal de Santa Catarina, 88040-900 Florianopolis, SC, Brazil \\ Correspondence should be addressed to Hamayun Khan; hamayun84@yahoo.com
}

Received 23 October 2015; Revised 15 January 2016; Accepted 18 January 2016

Academic Editor: Denis Delic

Copyright (C) 2016 Hamayun Khan et al. This is an open access article distributed under the Creative Commons Attribution License, which permits unrestricted use, distribution, and reproduction in any medium, provided the original work is properly cited.

\begin{abstract}
Two important biologically active compounds were isolated from Mallotus philippensis. The isolated compounds were characterized using spectroanalytical techniques and found to be bergenin (1) and 11-O-galloylbergenin (2). The in vitro antioxidant and antiplasmodial activities of the isolated compounds were determined. For the antioxidant potential, three standard analytical protocols, namely, DPPH radical scavenging activity (RSA), reducing power assay (RPA), and total antioxidant capacity (TAC) assay, were adopted. The results showed that compound 2 was found to be more potent antioxidant as compared to $\mathbf{1}$. Fascinatingly, compound 2 displayed better $\mathrm{EC}_{50}$ results as compared to $\alpha$-tocopherol while being comparable with ascorbic acid. The antiplasmodial assay data showed that both the compound exhibited good activity against chloroquine sensitive strain of Plasmodium falciparum (D10) and $\mathrm{IC}_{50}$ values were found to be less than $8 \mu \mathrm{M}$. The in silico molecular docking analyses were also performed for the determination of binding affinity of the isolated compounds using P. falciparum proteins PfLDH and Pfg27. The results showed that compound $\mathbf{2}$ has high docking score and binding affinity to both protein receptors as compared to compound 1. The demonstrated biological potentials declared that compound 2 could be the better natural antioxidant and antiplasmodial candidate.
\end{abstract}

\section{Introduction}

Medicinal plants, their extracts, or the isolated purified constituents have been used extensively as remedy for treatment of several diseases. The flora of Pakistan is quite rich with the naturally gifted medicinal plants. However, very little attention was given to explore the medicinal potentials of such worthy materia medica [1-3]. Various ailments such as Parkinson's, Alzheimer's, cancer, inflammation, neurodegeneration, aging, injury to blood vessel membranes, heart, and brain, and a number of other diseases may be caused by the free radicals present in the body. Antioxidants are free radical scavengers that may prevent, protect, or reduce the extension of such damage $[4,5]$. A number of chemical species including both synthetic and natural products may act as antioxidants. Plants are considered to be the best source of natural antioxidants $[1-3,6]$. Similarly, the various antimalarial and antiparasitic drugs such as quinine and artemisinin were also reported from the medicinal plants [7].

Bergenin and 11-O-galloylbergenin are the two natural products. The biological and pharmacological activities of bergenin are well documented in the literature [8-21]. However, very little work has been reported on the biological potentials of 11-O-galloylbergenin [22,23] which need to be more explored. In the present study, the abovementioned natural products were isolated from Mallotus philippensis and their antioxidant and antiplasmodial activities were investigated. For confirmation of the experimental results, the computational study was also performed using in silico molecular docking. 


\section{Materials and Methods}

2.1. General Experimental Procedures. ${ }^{1} \mathrm{H}-\mathrm{NMR}$ and ${ }^{13} \mathrm{C}-$ NMR were recorded at $400 \mathrm{MHz}$ for ${ }^{1} \mathrm{H}$ and at $100 \mathrm{MHz}$ for ${ }^{13} \mathrm{C}$ using TMS as internal standard with Bruker DPX400 instrument in deuterated solutions. Mass spectra were recorded on Agilent 5973N instrument using EI mode. IR spectra were determined using a Jasco A-302 spectrophotometer. UV and UV-visible spectra were recorded using U3200 (Hitachi, Japan) and SP-3000 PLUS (Optima, Japan) spectrophotometers. For TLC and column chromatography, aluminum sheets precoated with silica-gel 60 F254 $(20 \times$ $20 \mathrm{~cm}, 0.2 \mathrm{~mm}$ thick; E. Merck, Germany) and silica gel (200300 mesh), respectively, were used. The commercial solvents were used for extraction purpose and were redistilled. For the antioxidant and antiplasmodial activities, analytical grade reagents and chemicals were used.

2.2. Plant Material. The stem wood of M. philippensis (Euphorbiaceae) was collected from district Bunner located in the north of Pakistan in July 2006 and identified via Voucher Number 1013 (pup) by Professor Dr. Abdur Rashid, Department of Botany, University of Peshawar, Peshawar, Pakistan.

2.3. Extraction and Isolation. Air dried plant material was chopped, grinded, and extracted three times with commercial ethanol for $72 \mathrm{~h}$ which afforded $4.32 \%$ of the crude extract. From the crude extract, $n$-hexane soluble fraction was removed by solvent extraction with water. The aqueous fraction was then dried under vacuum which was further processed for the isolation of compounds $\mathbf{1}$ and $\mathbf{2}$ as depicted in Scheme 1. The isolated compounds were characterized using various spectroanalytical techniques.

2.4. Antioxidant Potential. The antioxidant potential of the isolated compounds was determined using $\mathrm{DPPH}$ radical scavenging activity (RSA) [1-3, 24], reducing power assay (RPA) $[24,25]$ and total antioxidant capacity (TAC) assay [26].

2.5. Antiplasmodial Activity. For antiplasmodial activity, the isolated compounds were tested against chloroquine sensitive (CQS) strain of Plasmodium falciparum (D10). Continuous in vitro cultures of asexual erythrocyte stages of $P$. falciparum were maintained using the reported method [27]. For the quantitative assessment of antiplasmodial activity, parasite lactate dehydrogenase assay was adopted [28]. The $\mathrm{IC}_{50}$ values were obtained using a nonlinear dose-response curve fitting analysis via Graph Pad Prism v.4.0 software.

2.6. Molecular Docking. For the in silico molecular docking study, the crystal structures of receptor proteins were downloaded from the protein data bank, code number PfLDH $(P$. falciparum lactate dehydrogenase) and PFG27 (gametocyte protein) of $P$. falciparum. The water molecules were removed and $3 \mathrm{D}$ protonation of the receptor molecules was carried out. The energies of the retrieved receptors were minimized using the default parameters of MOE energy minimization algorithm (gradient: 0.05, force field: MMFF94X). For the molecular docking of the isolated compounds, default parameters of MOE-dock program were used. To find the correct conformations of the ligands and to obtain minimum energy structure, ligands were allowed to be flexible. At the end of docking, the best conformations of the ligand were analyzed for their binding interactions.

\section{Results and Discussion}

3.1. Characterization of the Isolated Compounds. The spectral analyses of the two isolated compounds are summarized as follows.

Compound 1. White needles; $\mathrm{mp}=237^{\circ} \mathrm{C} ; \mathrm{UV} \lambda_{\max }(\log \varepsilon)=$ 279(4.28); IR (KBr) $\lambda_{\max }=3310,3350,1712,1632,1609,1510$, $1230 \mathrm{~cm}^{-1}$; ${ }^{1} \mathrm{H}-\mathrm{NMR}\left(\mathrm{DMSO}-\mathrm{d}_{6}, 400 \mathrm{MHz}\right): \delta 6.97(1 \mathrm{H}, \mathrm{s}, \mathrm{H}-$ 7), 5.67 (1H, d, H-10b), 4.98 (1H, dd, H-4a), 3.89 (1H, dd, H-4), 3.81 (2H, d, H-11), 3.75 (3H, s, H-12), 3.62 (1H, m, H-2), 3.48 $(1 \mathrm{H}, \mathrm{dd}, \mathrm{H}-3) ;{ }^{13} \mathrm{C}-\mathrm{NMR}$ (DMSO- $\left.\mathrm{d}_{6}, 100 \mathrm{MHz}\right): \delta 60.0(\mathrm{C}-$ 12), 61.1 (C-11), 70.7 (C-3), 72.1 (C-10b), 73.7 (C-4), 79.8 (C4a), 81.7 (C-2), 109.4 (C-7), 116.0 (C-10a), 118.1 (C-6a), 140.6 (C-9), 148.1 (C-10), 151.0 (C-8), 163.5 (C-6); EIMS m/z (rel. int.): 328 (34), 208 (100), 237 (7), 170 (30).

Compound 1 was obtained as white crystals. The mass spectral data of compound 1 gave a molecular ion peak at $\mathrm{m} / z$ 328 which leads to a molecular formula of $\mathrm{C}_{14} \mathrm{H}_{16} \mathrm{O}_{9}$. The melting point of $237^{\circ} \mathrm{C}$ is consistent with the published melting point of bergenin, that is, $238^{\circ} \mathrm{C}$. The ${ }^{1} \mathrm{H}-\mathrm{NMR}$ spectral analysis showed a signal for one aromatic proton at $\delta 6.97(1 \mathrm{H}$, s) and a signal for methoxy protons at $\delta 3.8(3 \mathrm{H}, \mathrm{s})$. In the ${ }^{13} \mathrm{C}$ NMR spectrum, the signals were observed at $\delta 163.5$ and 60.0 for carbonyl and methoxy groups, respectively. Compound 1 was characterized as bergenin (Figure 1) by comparing its physical and spectral data with previous literature [23, 29].

Compound 2. White amorphous powder; $\mathrm{mp}=180^{\circ} \mathrm{C}$; $[\alpha]_{\mathrm{D}}{ }^{15}=+37.6^{\circ}(\mathrm{EtOH} ; \mathrm{c} 1.2)$, UV $\lambda_{\max }(\log \varepsilon)=277(4.22)$; IR $(\mathrm{KBr}) \lambda_{\max }=3310,1712,1632,1609,1510,1230 \mathrm{~cm}^{-1} ;{ }^{1} \mathrm{H}-$ NMR (90 MHz, Me $\left.{ }_{2} \mathrm{CO}-\mathrm{d}\right): \delta 7.21(2 \mathrm{H}, \mathrm{s}$, gall-H), $7.10(\mathrm{IH}$, s, H-7), 3.90 (3H, s, OMe); ${ }^{13} \mathrm{C}-\mathrm{NMR}\left(90 \mathrm{MHz}, \mathrm{CD}_{3} \mathrm{OD}\right)$ : $\delta 81.2$ (C-2), 72.2 (C-3), 75.7 (C-4), 81.1 (C-4a), 166.5(C-6), 120.0, (C-6a), 112.0 (C-7), 153.1 (C-8), 143.3 (C-9), 150.0 (C10), 117.7 (C-10a), 74.7 (C-10b), 65.1 (C-11), 61.3 (C-12), 121.8 $\left(\mathrm{C}-1^{\prime}\right), 111.1\left(\mathrm{C}-2^{\prime}, \mathrm{C}-6^{\prime}\right), 147.4\left(\mathrm{C}-3^{\prime}, \mathrm{C}-5^{\prime}\right), 140.0\left(\mathrm{C}-4^{\prime}\right), 169.2$ (C-7' ${ }^{\prime}$ ); EIMS $m / z$ (rel. int.): 480 (32), 328 (34), 208 (100), 237 (7), $170(30)$.

Compound 2 was interpreted and analyzed as $\mathrm{C}_{21} \mathrm{H}_{20} \mathrm{O}_{13}$ to be monogalloyl ester of bergenin by its ${ }^{1} \mathrm{H}-\mathrm{NMR},{ }^{13} \mathrm{C}$ NMR, and EIMS spectral data and also by acid hydrolysis which gave bergenin and gallic acid. The position of the galloyl group was established by ${ }^{13} \mathrm{C}-\mathrm{NMR}$ spectrum and $2 \mathrm{D}$ techniques. The carbon signals other than that of C-11 in the glucose moiety of bergenin were assigned as given below. The carbon carrying free hydroxyl group (C-3, C-4, and C-11) was unequivocally distinguished from the others (C-2, C-4a, and $\mathrm{C}-10 \mathrm{~b})$ by the deuterium induced differential isotope shift 


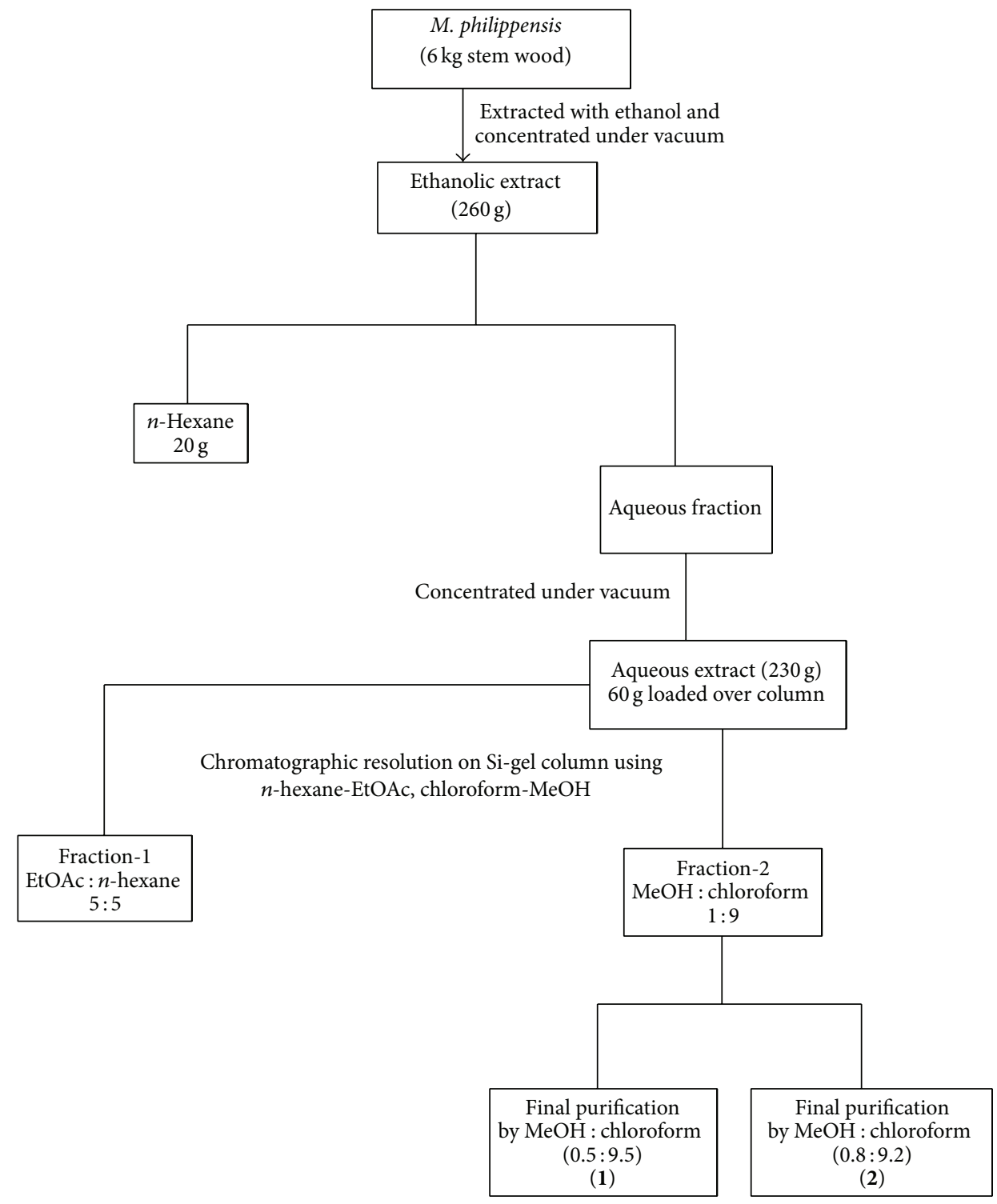

Scheme 1: Schematic representation of extraction and isolation of compounds $\mathbf{1}$ and $\mathbf{2}$ from Mallotus philippensis stem wood.<smiles>COc1c(O)cc2c(c1O)C1O[C@H](CO)[C@@H](O)[C@H](O)[C@H]1OC2=O</smiles><smiles>COc1c(O)cc2c(c1O)C1O[C@H](COC(=O)c3cc(O)c(O)c(O)c3)[C@@H](O)[C@H](O)[C@H]1OC2=O</smiles>

FIGURE 1: Chemical structure of isolated compounds 1 (bergenin) and 2 (11-O-galloylbergenin). 
TABLE 1: Antioxidant activity of the isolated compounds and standards.

\begin{tabular}{lccc}
\hline Tested compounds & \% radical scavenging activity (RSA) & Reducing power assay (RPA) & Total antioxidant capacity $^{*}$ \\
\hline Bergenin (1) & $6.858 \pm 0.329$ & $0.055 \pm 0.002$ & $49.159 \pm 3.136$ \\
11-O-Galloylbergenin (2) & $87.26 \pm 1.671$ & $1.315 \pm 0.027$ & $951.50 \pm 109.64$ \\
Ascorbic acid & $97.85 \pm 0.623$ & $3.351 \pm 0.034$ & $2478.36 \pm 173.81$ \\
Gallic acid & $98.12 \pm 0.931$ & $1.435 \pm 0.031$ & $2201.05 \pm 152.33$ \\
Quercetin & $98.35 \pm 0.871$ & $1.772 \pm 0.041$ & $2030.29 \pm 134.51$ \\
$\alpha$-Tocopherol & $92.26 \pm 0.547$ & $22.026 \pm 0.074$ & $565.17 \pm 25.32$ \\
\hline
\end{tabular}

Each reading is mean $(n=3) \pm \mathrm{SD}$ (standard deviation). For RSA and RPA, 100 and $25 \mu \mathrm{g} / \mathrm{mL}$, respectively, were used. ${ }^{*}$ As ascorbic acid equivalent $(\mu \mathrm{mol} / \mathrm{mg})$.

TABLE 2: $\mathrm{EC}_{50}$ values of the isolated compounds and standards.

\begin{tabular}{lcc}
\hline Tested compounds & Radical scavenging assay $\left(\mathrm{EC}_{50}\right)(\mu \mathrm{g} / \mathrm{mL})^{\mathrm{a}}$ & Reducing power assay $\left(\mathrm{EC}_{50}\right)(\mu \mathrm{g} / \mathrm{mL})^{\mathrm{b}}$ \\
\hline Bergenin $(\mathbf{1})$ & $99.807 \pm 3.120$ & $24.915 \pm 1.326$ \\
11-O-Galloylbergenin (2) & $7.276 \pm 0.058$ & $5.208 \pm 0.095$ \\
Ascorbic acid & $6.571 \pm 0.303$ & $3.551 \pm 0.073$ \\
Gallic acid & $4.732 \pm 0.187$ & $1.542 \pm 0.062$ \\
Quercetin & $4.355 \pm 0.099$ & $2.073 \pm 0.065$ \\
$\alpha$-Tocopherol & $33.675 \pm 2.019$ & $22.152 \pm 1.153$ \\
\hline
\end{tabular}

Each reading is mean $(n=3) \pm \mathrm{SD}$ (standard deviation). ${ }^{\mathrm{a}} \mathrm{EC}_{50}$ : effective concentration at which $50 \%$ of DPPH radicals are scavenged and ${ }^{\mathrm{b}} \mathrm{EC}_{50}$ : effective concentration at which the absorbance is 0.4 .

(DIS) measurement. Compound 2 was characterized as $11-O$ galloylbergenin (Figure 1) [23, 30].

3.2. Antioxidant Activity. In DPPH radical scavenging assay, the isolated compounds 1 and 2 showed $6.858 \pm 0.329$ and $87.26 \pm 1.671 \% \mathrm{RSA}$, respectively when compared with the selected standards whose \%RSA were in the range from $92.26 \pm 0.547$ to $98.35 \pm 0.871$ (Table 1 ). The demonstrated \%RSA of compound $\mathbf{2}$ clearly indicates that it is the high potency toward DPPH free radical. Similarly, in the RPA, the reducing power capacity of compound 2 was found to be much higher as compared to compound $\mathbf{1}$ while being comparable with gallic acid and quercetin as depicted in Table 1. The TAC of the isolated compounds and standards was determined as ascorbic acid equivalent as shown in Table 1. As can be seen from the results, again compound $\mathbf{2}$ displayed better activity as compared to compound $\mathbf{1}$ and even $\alpha$-tocopherol. From the above discussion, compound 2 could be declared as the better antioxidant candidate. The antioxidant properties of various plants extract or their purified constituents are well documented in the literature [1$3,6,22,24,31-34]$.

Table 2 shows a comparative analysis of $\mathrm{EC}_{50}$ values of the isolated compounds and standards using $\mathrm{DPPH}$ radical scavenging and reducing power assays. The $\mathrm{EC}_{50}$ values showed more prominent performance of compound $\mathbf{2}$ as compared to compound $\mathbf{1}$. For the studied assays data, the $\mathrm{EC}_{50}$ vales for compound 2 showed better results as compared to $\alpha$-tocopherol while being comparable with the ascorbic acid (Table 2 ). In a previous study, the antioxidant activity of various compounds isolated from the methanolic extract of the aerial parts of Vitex agnus-castus Linn. plant was evaluated using a DPPH radical scavenging assay and the results obtained were in the range from no activity to strong
TABLE 3: The in vitro antiplasmodial activity of the isolated compounds and standard.

\begin{tabular}{lc}
\hline Tested compounds & Antiplasmodial activity $\left(\mathrm{IC}_{50}\right.$ in $\left.\mu \mathrm{M}\right)$ \\
\hline Bergenin (1) & $6.92 \pm 0.43$ \\
11-O-Galloylbergenin (2) & $7.85 \pm 0.61$ \\
Chloroquine & $0.031 \pm 0.002$ \\
\hline
\end{tabular}

Each reading is mean $(n=3) \pm \mathrm{SD}$ (standard deviation).

activity. However, the $\mathrm{IC}_{50}$ value was not reported [6]. The results obtained in the present study are comparable with the reported data [22].

3.3. Antiplasmodial Activity. Compounds $\mathbf{1}$ and $\mathbf{2}$ were also tested for the in vitro antiplasmodial activity against the CQS D10 strain of $P$. falciparum and the results obtained are presented in Table 3. As can be seen, both the tested compounds had displayed good activity even at low concentration with $\mathrm{IC}_{50}$ values of $6.92 \pm 0.43$ and $7.85 \pm 0.61 \mu \mathrm{M}$ for compounds 1 and 2, respectively, while $\mathrm{IC}_{50}$ value of $0.031 \pm 0.002 \mu \mathrm{M}$ was recorded for chloroquine (Table 3 ). The analogous results were also reported previously for mentioned compounds isolated from the roots of Bergenia ligulata.

3.4. Molecular Docking. The binding interaction of the isolated compounds and $P$. falciparum proteins (PfLDH and Pfg27) was also investigated using in silico molecular docking. The selected proteins are very important because PfLDH has a role in glycolysis for energy production during asexual cycle, while Pfg27 is vital protein for the gametocyte production during sexual phase of the parasite; thus both proteinsare potential molecular targets for antimalarial drugs. The results of molecular docking with compound $\mathbf{1}$ and 
TABLE 4: The in silico docking score of the isolated compounds against P. falciparum proteins (PfLDH and Pfg27).

\begin{tabular}{|c|c|c|c|c|}
\hline \multirow{3}{*}{ Isolated compounds } & \multicolumn{4}{|c|}{ Docking result Moldock score } \\
\hline & \multicolumn{2}{|c|}{ PfLDH } & \multicolumn{2}{|c|}{ PfG27 } \\
\hline & Moldock score & Binding affinity (pKi) & Moldock score & Binding affinity (pKi) \\
\hline 1 & -12.13 & 10.20 & -10.01 & 8.78 \\
\hline 2 & -16.22 & 12.43 & -11.84 & 9.29 \\
\hline
\end{tabular}

PfLDH showed that compound was bound in the binding pocket of the enzyme, making interactions with the residues Lys198, Arg109, Asn108, and Asn197 (basic, side chain donors and backbone donor). Lys 98 interacts with oxygen of one hydroxyl group of ring and Arg109 with other hydroxyl group oxygen while oxygen of third hydroxyl group established interaction with the Asn197 whereas the oxygen atom of the ring interacts with Asn108 (Figure S2 in Supplementary Material available online at http://dx.doi.org/10.1155/ 2016/1051925). Compound 2 was completely docked in cavity of the enzyme PfLDH and established large number of interactions with the residues Arg185, Ser170, Glu256, Lys173, Val166, Gly165, Thr169, Ala253, and Ala249. In the above docking process, the residue Arg185 formed three interactions, that is, one with oxygen of one hydroxyl group of benzene ring, the second with oxygen of carboxylic group of compound 2 , and the third (arene-arene interaction) with benzene ring. The residue Ser170 established two interactions (backbone donor and acceptor) with hydrogen of hydroxyl group of two cyclic rings and one with oxygen of hydroxyl group of benzene ring of compound 2. The residue Glu256 showed interaction with the hydrogen atom of benzene hydroxyl group (side chain acceptor) and Lys173 has two interactions (side chain donor) with the two oxygen atoms of two hydroxyl groups of benzene ring. The residue Gly165 formed one interaction with hydrogen of hydroxyl group of benzene ring and residue Thr169 (side chain acceptor) showed one interaction with hydrogen of one hydroxyl group. Val166 (backbone acceptor) formed two interactions with the two hydrogen atoms of one hydroxyl group of one benzene ring and with the other hydroxyl group of another benzene ring. Ala253 and Ala249 (backbone donor) both expressed interactions with oxygen of hydroxyl group and carboxyl group (Figure S3).

The results of molecular docking of compound $\mathbf{1}$ and Pfg27 protein binding showed that $\mathbf{1}$ was bound into the binding cavity of protein (Pfg27) making interactions with the residues Arg131 (basic, side chain donor) and Asp40. Arg131 interacts with oxygen (carboxyl group) to one side of benzene ring while Asp40 was found in polar interaction with $\mathrm{H}$ (hydroxyl group) of compound 1 (Figure S4). Similarly, Arg36 residue also showed prominent interaction with oxygen of hydroxyl group as shown in Figure S5. In case of compound 2, Arg131 residue established arene-cation interaction with one of the benzene rings of compound and the residue Glu134 formed three-side interaction, that is, two sides with hydrogen of two hydroxyl groups and one side with one oxygen group of carboxyl group (Figure S6). Further, compound $\mathbf{2}$ also showed arene-arene interaction the residue His28, while Arg36 and Gln130 formed interaction with hydrogen of hydroxyl groups (Figures S7 and S8). From the MOE-docking studies, it was observed that, for both the proteins, compound $\mathbf{2}$ has good agreement of docking score and binding affinity to protein receptors as compared to compound $\mathbf{1}$ as shown in Table 4. The results demonstrated that the isolated compounds are good enough for their potency and effectiveness against $P$. falciparum.

\section{Conclusions}

The current study deals with the isolation and characterization of two biologically active compounds from M. philippensis. The natural products were found to be bergenin (1) and 11-O-galloylbergenin (2). The isolated constituents were evaluated for their antioxidant and antiplasmodial potentials and from the results it was evident that compound $\mathbf{2}$ was found to be a potent and effective antioxidant as compared to compound $\mathbf{1}$ and its synthetic derivatives $[8,30]$. The isolated compounds also offered good antiplasmodial activity against the tested $P$. falciparum strain which was further confirmed using in silico molecular docking. It is therefore concluded that the demonstrated medicinal properties of the isolated compounds could be used as scaffolds for the generation of advanced natural products and may play a vital role in drug development and design.

\section{Conflict of Interests}

The authors declare that there is no conflict of interests regarding the publication of this paper.

\section{References}

[1] T. Khan, M. Ahmad, R. Khan, H. Khan, A. Ejaz, and M. I. Choudhary, "Evaluation of phytomedicinal potentials of selected plants of Pakistan," American Laboratory, vol. 38, no. 9, pp. 20-22, 2006.

[2] M. Imran, H. Khan, M. Shah, R. Khan, and F. Khan, "Chemical composition and antioxidant activity of certain Morus species," Journal of Zhejiang University: Science B, vol. 11, no. 12, pp. 973980, 2010.

[3] I. Hussain, H. Khan, and M. A. Khan, "Screening of selected medicinal plants for the antioxidant potential," Pakistan Journal of Scientific and Industrial Research, vol. 53, no. 6, pp. 338-339, 2010.

[4] T. Finkel and N. J. Holbrook, "Oxidants, oxidative stress and the biology of ageing," Nature, vol. 408, no. 6809, pp. 239-247, 2000.

[5] J. A. Knight, "Diseases related to oxygen-derived free radicals," Annals of Clinical \& Laboratory Science, vol. 25, no. 2, pp. 111121, 1995. 
[6] Azizuddin, T. Makhmoor, and M. I. Choudhary, "Radical scavenging potential of compounds isolated from Vitex agnuscastus," Turkish Journal of Chemistry, vol. 34, no. 1, pp. 119-126, 2010.

[7] C. W. Wright and J. D. Phillipson, "Natural products and the development of selective antiprotozoal drugs," Phytotherapy Research, vol. 4, no. 4, pp. 127-139, 1990.

[8] H. Takahashi, M. Kosaka, Y. Watanabe, K. Nakade, and Y. Fukuyama, "Synthesis and neuroprotective activity of bergenin derivatives with antioxidant activity," Bioorganic and Medicinal Chemistry, vol. 11, no. 8, pp. 1781-1788, 2003.

[9] X. Piegen, "Traditional experience of Chinese herb medicine. Its applications in drug research and new drug searching," in Natural Products as Medicinal Agents, J. L. Beal and E. Reinhard, Eds., Hippokrates, Stuttgart, Germany, 1980.

[10] M. A. F. Jahromi, J. P. N. Chansouria, and A. B. Ray, "Hypolipidaemic activity in rats of bergenin, the major constituent of Flueggea microcarpa," Phytotherapy Research, vol. 6, no. 4, pp. 180-183, 1992.

[11] S. Piacente, C. Pizza, and N. De Tommasi, "Constituents of Ardisia japonica and their in vitro anti-HIV activity," Journal of Natural Products, vol. 59, no. 6, pp. 565-569, 1996.

[12] H.-L. Pu, X. Huang, J.-H. Zhao, and A. Hong, "Bergenin is the antiarrhythmic principle of Fluggea virosa," Planta Medica, vol. 68, no. 4, pp. 372-374, 2002.

[13] T. Swarnalakshmi, M. G. Sethuraman, N. Sulochana, and R. Arivudainambi, "A note on the anti-inflammatory activity of bergenin," Current Science, vol. 53, no. 17, p. 917, 1984.

[14] Y.-F. Li, L.-H. Hu, F.-C. Lou, J. Li, and Q. J. Shen, "PTP1B inhibitors from Ardisia japonica," Journal of Asian Natural Products Research, vol. 7, no. 1, pp. 13-18, 2005.

[15] R. K. Goel, R. N. Maiti, M. Manickam, and A. B. Ray, "Antiulcer activity of naturally occurring pyrano-coumarin and isocoumarins and their effect on prostanoid synthesis using human colonic mucosa," Indian Journal of Experimental Biology, vol. 35, no. 10, pp. 1080-1083, 1997.

[16] N. Nazir, S. Koul, M. A. Qurishi et al., "Immunomodulatory effect of bergenin and norbergenin against adjuvant-induced arthritis-a flow cytometric study," Journal of Ethnopharmacology, vol. 112, no. 2, pp. 401-405, 2007.

[17] Y. Y. Lee, D. S. Jang, J. L. Jin, and H. S. Yun-Choi, "Antiplatelet aggregating and anti-oxidative activities of $11-\mathrm{O}-\left(4^{\prime}\right.$ $O$-methylgalloyl)-bergenin, a new compound isolated from Crassula cv. 'Himaturi', Planta Medica, vol. 71, no. 8, pp. 776$777,2005$.

[18] Y.-H. Zhang, L.-H. Fang, M.-K. Lee, and B.-S. Ku, "In vitro inhibitory effects of bergenin and norbergenin on bovine adrenal tyrosine hydroxylase," Phytotherapy Research, vol. 17, no. 8, pp. 967-969, 2003.

[19] H.-K. Lim, H.-S. Kim, H.-S. Choi, S. Oh, and J. Choi, "Hepatoprotective effects of bergenin, a major constituent of Mallotus japonicus, on carbon tetrachloride-intoxicated rats," Journal of Ethnopharmacology, vol. 72, no. 3, pp. 469-474, 2000.

[20] H.-K. Lim, H.-S. Kim, H.-S. Choi, J. Choi, S.-H. Kim, and M.-J. Chang, "Effects of bergenin, the major constituent of Mallotus japonicus against D-galactosamine-induced hepatotoxicity in rats," Pharmacology, vol. 63, no. 2, pp. 71-75, 2001.

[21] B. Prithiviraj, U. P. Singh, M. Manickam, J. S. Srivastava, and A. B. Ray, "Antifungal activity of bergenin, a constituent of Flueggea microcarpa," Plant Pathology, vol. 46, no. 2, pp. 224228, 1997.
[22] G. Uddin, A. Sadat, and B. S. Siddiqui, "Comparative antioxidant and antiplasmodial activities of 11-O-galloylbergenin and bergenin isolated from Bergenia ligulata," Tropical Biomedicine, vol. 31, no. 1, pp. 143-148, 2014.

[23] M. Arfan, H. Amin, N. Khan et al., "Analgesic and antiinflammatory activities of 11-O-galloylbergenin," Journal of Ethnopharmacology, vol. 131, no. 2, pp. 502-504, 2010.

[24] H. Khan, S. A. Jan, M. Javed et al., "Nutritional composition, antioxidant and antimicrobial activities of selected wild edible plants," Journal of Food Biochemistry, vol. 40, no. 1, pp. 61-70, 2016.

[25] M. Oyaizu, "Studies on product of browning reaction: antioxidative activities of product of browning reaction prepared from glucosamine," Japan Journal of Nutrition, vol. 44, no. 6, pp. 307315, 1986.

[26] P. Prieto, M. Pineda, and M. Aguilar, "Spectrophotometric quantitation of antioxidant capacity through the formation of a phosphomolybdenum complex: specific application to the determination of vitamin E," Analytical Biochemistry, vol. 269, no. 2, pp. 337-341, 1999.

[27] W. Trager and J. B. Jensen, "Human malaria parasites in continuous culture," Science, vol. 193, no. 4254, pp. 673-675, 1976.

[28] M. T. Makler, J. M. Ries, J. A. Williams et al., "Parasite lactate dehydrogenase as an assay for Plasmodium falciparum drug sensitivity," The American Journal of Tropical Medicine and Hygiene, vol. 48, no. 6, pp. 739-741, 1993.

[29] E. Akbar, A. Malik, N. Afza, and S. M. A. Hai, "Flavone glycosides and bergenin derivatives from Tridax procumbens," Heterocycles, vol. 57, no. 4, pp. 733-739, 2002.

[30] T. Yoshida, K. Seno, Y. Takama, and T. Okuda, "Bergenin derivatives from Mallotus japonicus," Phytochemistry, vol. 21, no. 5, pp. 1180-1182, 1982.

[31] J.-C. Ho, "Antimicrobial, mosquito larvicidal and antioxidant properties of the leaf and rhizome of Hedychium coronarium," Journal of the Chinese Chemical Society, vol. 58, no. 4, pp. 563$567,2011$.

[32] J. Wang, S. Hu, S. Nie, Q. Yu, and M. Xie, "Reviews on mechanisms of in vitro antioxidant activity of polysaccharides," Oxidative Medicine and Cellular Longevity, vol. 2016, Article ID 5692852, 13 pages, 2016.

[33] A. Elmann, A. Telerman, H. Erlank et al., "Protective and antioxidant effects of a chalconoid from Pulicaria incisa on brain astrocytes," Oxidative Medicine and Cellular Longevity, vol. 2013, Article ID 694398, 10 pages, 2013.

[34] D. Sreeramulu, C. V. K. Reddy, A. Chauhan, N. Balakrishna, and M. Raghunath, "Natural antioxidant activity of commonly consumed plant foods in India: effect of domestic processing," Oxidative Medicine and Cellular Longevity, vol. 2013, Article ID 369479, 12 pages, 2013. 


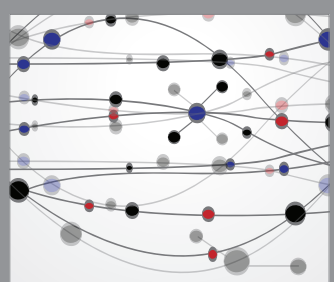

The Scientific World Journal
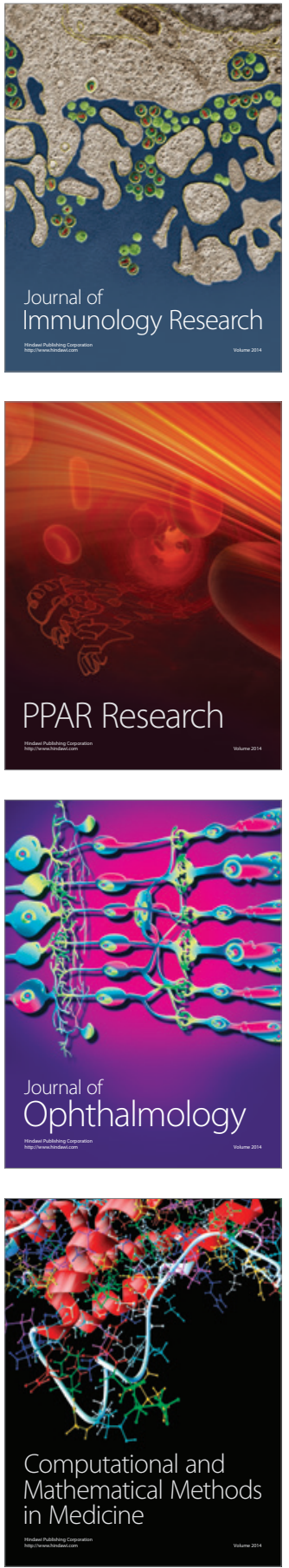

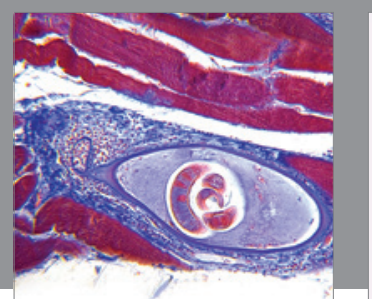

Gastroenterology Research and Practice

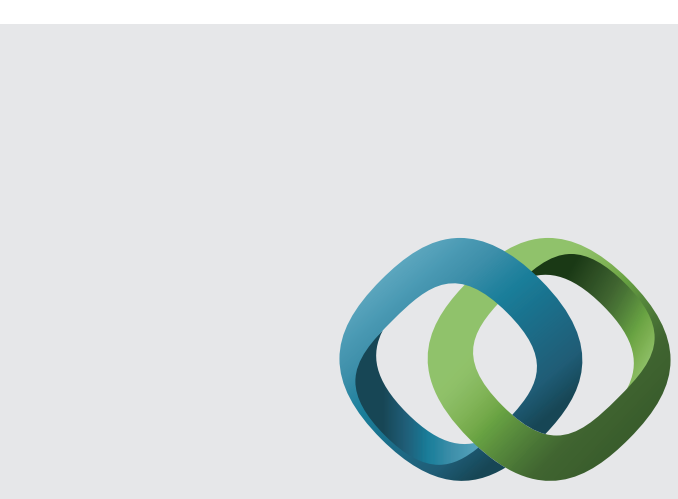

\section{Hindawi}

Submit your manuscripts at

http://www.hindawi.com
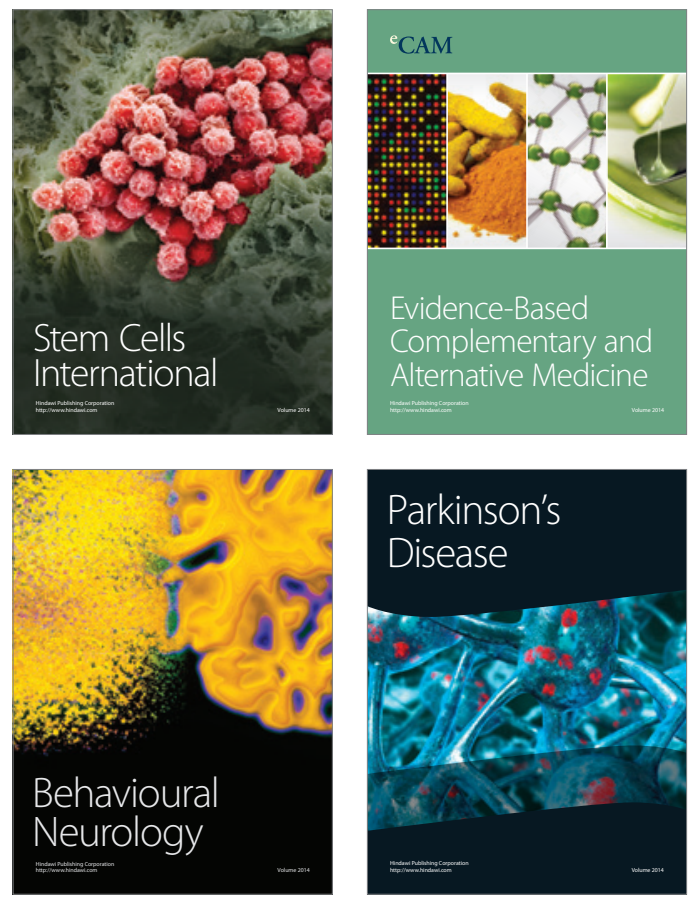
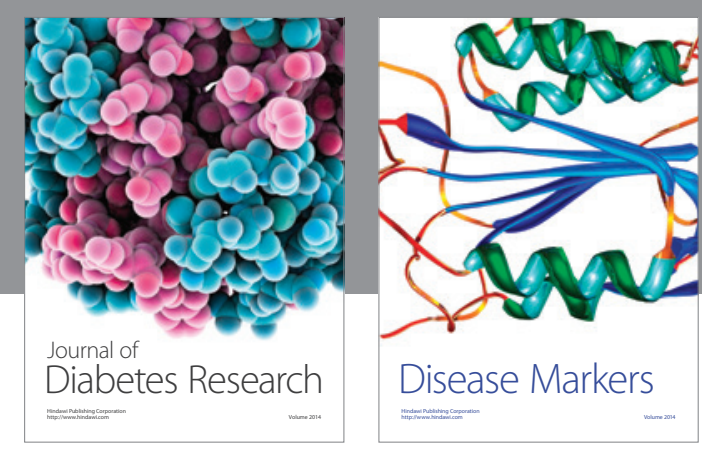

Disease Markers
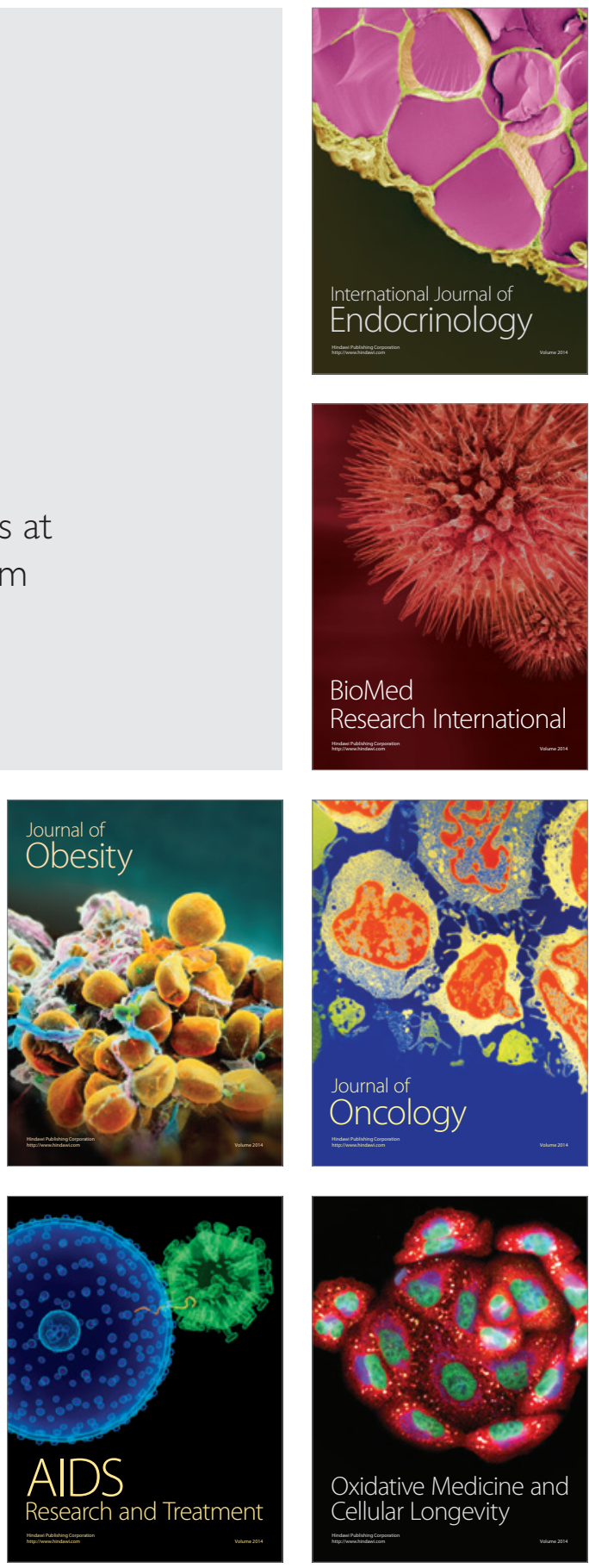